\title{
Research Progress of Wind/PV Hybrid Technology and its Application in Intelligent Greenhouse
}

\author{
Bing Li \\ School of Mechanical Engineering, Baicheng Normal University, Baicheng City, Jilin province, 137000, \\ China
}

Keywords: The Wind/PV Hybrid; Research progress; Intelligent greenhouse; Power supply system; Sprinkler system

\begin{abstract}
The rapid growth of population and energy consumption has led to a series of problems, such as energy shortage, environmental pollution and ecological deterioration. Making full use of renewable energy and achieving sustainable economic development has become the consensus of all countries in the world. Wind and solar energy are the most widely used among all kinds of the renewable resources. The Wind/PV Hybrid Generation System utilizes the hybrid of wind energy and solar energy in time and season distribution to generate electricity, and has good stability of output power and wide application prospect. Based on the author's learning and practical experience, this paper first analyzed the research and development of WPHGS, and then discussed the application of Wind/PV Hybrid technology in the intelligent greenhouse power supply and spray system.
\end{abstract}

\section{Introduction}

Wind/PV Hybrid technology is a kind of diversified development pattern, which is a combination of wind and solar power generation industry and agricultural industries. It is composed of wind turbines, solar panel, battery, controller, inverter and other accessories. The Wind/PV Hybrid of power supply and agricultural greenhouse sprinkler system combines wind and solar power generation with agricultural cultivation and the utility model is provided with a wind-driven generator outside the shed, and a solar panel is installed at the roof of the shed to replace the partial PC plate or toughened glass. The system effectively utilizes the top space of greenhouses and plants cash crops in greenhouse. It uses limited resources and space to improve the economic benefits of unit land. It is a new type of agricultural greenhouse, which can directly use the farmland directly to generate electricity and not affect the normal growth of the crops in the greenhouse. It opens a new pattern of low carbon agriculture development, which has good economic and ecological benefits with a bright future.

\section{Research and Development of WPHGS}

In 1981, N.E.Busch of Denmark put forward the technical problems of solar energy and wind energy hybrid utilization. The original WPHGS simply combines wind turbines with photovoltaic modules. Subsequently, the American C.I. Aspliden studied the Meteorological Problems of the solar wind hybrid conversion system; N.Aksarni of the former Soviet Union estimated the approximate value of solar wind energy potential based on the probability principle and provided scientific data support for the research and utilization of the WPHGS; in 1982, Chinese Yu Huayang and others proposed energy conversion devices for solar wind power generators, which makes the study of the WPHGS then entered the stage of actual utilization.

With the deepening of the research on WPHGS, a batch of preliminary research results have been produced. In the aspect of software development, it mainly due to the Rodolfo and Dufo Lopez at Zaragoza university in Spain, and they use $\mathrm{C}++$ language developed for scenery, optimizing system based on genetic algorithm machine light diesel hybrid power system (software). Hybrid 2 
itself is a very good software for very accurate simulation run in the Wind/PV Hybrid System. Moreover, it gets 1 year, 8760 hour simulated running results according to the input hybrid power generation system structure, load characteristics, and installation site wind speed and the solar radiation data. In recent years, domestic and foreign research on WPHGS mainly focuses on the optimization design and reasonable allocation of the system. In foreign countries, Rajesh Kark at Saskatchewan university in Canada studied the cost and reliability of an independent small scale solar power generation system and obtained a reasonable allocation of power generation systems based on load and scenic resource conditions. It is an important way to reduce the cost of power generation and improve the system reliability. He also pointed out the feasibility of the capacity expansion of the hybrid generation system. In China, Hong Kong Polytech University, the Chinese Academy of Sciences in Guangzhou Energy Institute and its semiconductor research institute have cooperated and proposed a set of methods for optimizing the design of WPHGS by using CAD. The method uses a more accurate characterization of component characteristics and evaluates the mathematical model of the actual acquired wind and PV resource, and finds out the system configuration with the minimum equipment investment cost to meet the user's electricity demand. In addition, the Energy Institute of HeFei University of Technology proposed variable structure simulation model of WPHGS, and the user can reconstruct the computer simulation of various structures and WPHGS, which can predict the performance of the system, the controlling strategy and the rationality of system operation efficiency etc. A new type of brushless doubly fed generator has been designed by South China University of Technology, and the optimal power transmission of the solar inverter has been realized by weight adjustment. In other Asian countries, Thailand researchers used the TRNSYS16 transient simulation software to evaluate the cost of a WPHGS. Researchers in Malaysia used genetic algorithms to analyze and optimize net cost minimization and allocation. Researchers in Bangladesh have optimized the power generation system based on Quasi Newton algorithm.

The researchers also carried out research and analysis on the existing Wind/PV Hybrid power station in china. College of mechanical and power engineering in Shanghai Jiao Tong University made a survey on the use of renewable energy power generation systems ( the general name of independent wind, independent solar and WPHGS), and herdsman's economic condition in the Inner Mongolia Autonomous Region Right Banner of Xilinguole Meng pastoral area. They also analyzed the problems and causes in the process of popularizing household renewable energy power generation systems, and pointed out that the system still needs to be optimized further to improve the reliability of the whole system. China Satellite Communications Corporation analyzed the practical operation for the WPHGS in Qinghai village to village project. After 1 years of operation, the system has completed the task of planning and showed very good economic benefits. At the same time, it points out that there are still some problems in the accuracy and reliability of the system.

Breakthroughs have also been made in the field of application of WPHGS. Both CNOOC and northwest oil field branch of Sinopec have made feasibility study on the development of marginal WPHGS for marginal oil field. The particularity of offshore oil field and several factors that need to be considered in engineering application are analyzed. Mobile communications, Chinese Academy of Agricultural Mechanization Sciences, Fujian yucoo Communication Technology Co. Ltd, Xinjiang new energy Limited by Share Ltd for power supply equipment in a certain area of mobile communication resource conditions and construction difficult problem, given a typical configuration of mobile communication to WPHGS. In the aspect of monitoring, Guangzhou Southern China Luqiao Industrial Co., Ltd. introduced the present situation of the use of WPHGS for monitoring cameras in our country, and proposed measures for improvement

\section{Application of Wind/PV Hybrid Technology in Intelligent Greenhouse}

Working principle and construction of the Wind/PV Hybrid technology. The power supply and spray system of the Wind/PV Hybrid agricultural greenhouse is a small wind power generator and solar cell module, which serves as the main covering material for the roof of the greenhouse. It 
provides energy for heating, cooling, dimming, shading and irrigation systems. It has a flexible greenhouse that regulates and controls the light in the greenhouse, the temperature and humidity of the air and the soil, and the concentration of carbon dioxide. Even in the cold season, you can also rely on the sun to maintain a certain temperature indoors and to meet the needs of vegetable crop growth. Its remaining electrical power can be incorporated into the national grid for sale or stored by the battery for night use. The working principle is shown in Figure 1.

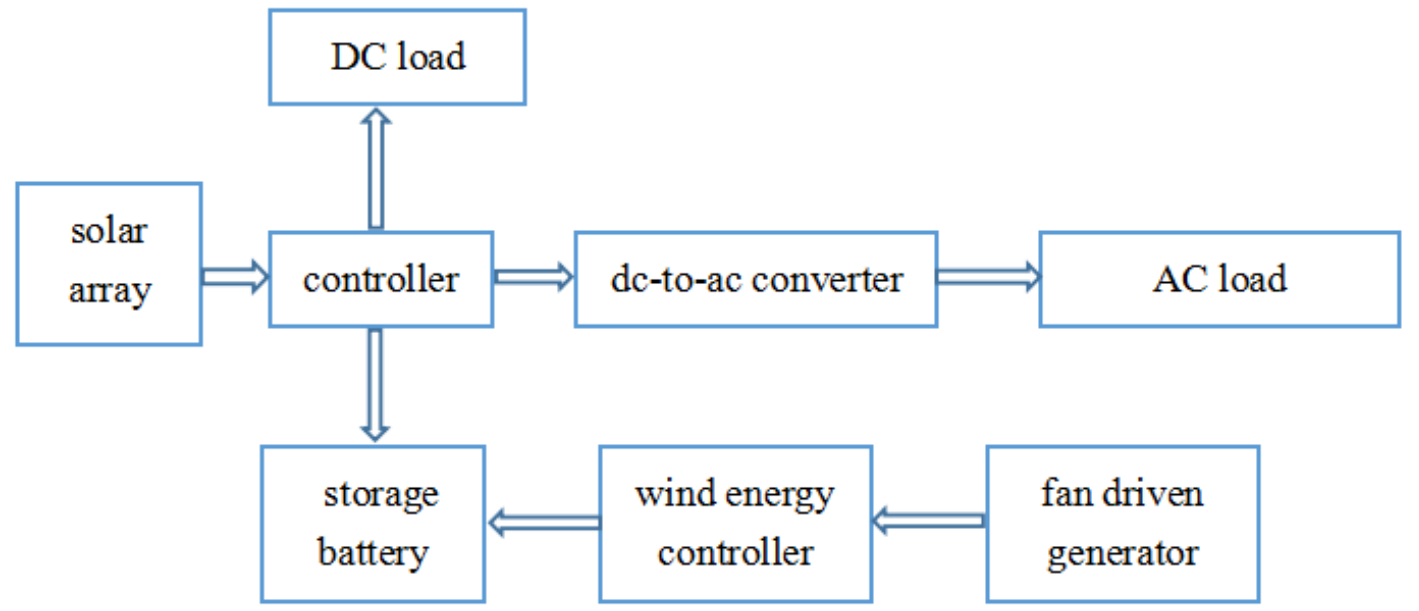

Fig.1 Working principle of the Wind/PV Hybrid technology

Construction of intelligent greenhouse system. The first is introduction of power supply system. The power supply and spray system of the Wind/PV Hybrid agricultural greenhouse consists of small horizontal axis wind turbine wind start, amorphous silicon thin film solar cell components, installation of steel structure roof grid connected inverter, AC (DC) flow distribution equipment, data acquisition and monitoring system, bidirectional inverter charger, battery, cable and cable bridge frame. Second is the main structure of the greenhouse. The main structure of the greenhouse is made of galvanized steel skeleton. The southern side of the top covering material of the greenhouse adopts light transmission or semi transparent amorphous silicon film photovoltaic component, and is connected with the steel structure skeleton by a special flexible connecting piece, and the rest of the shed top adopts toughened glass. It uses polycarbonate board (PC board) around the wall. There are windows around the wall of the solar greenhouse, and a door is opened for each thing to cool down. Third, greenhouse system optional configuration: the cooling principle of wet curtain cooling system is that when the water flows through the wet curtain, a water film is formed on the surface of the wet curtain, and the water film and the air passing through are exchanged for heat, and the principle of evaporation and cooling is adopted to evaporate water into the air, thereby reducing air temperature and increasing air humidity. Control the temperature and humidity of the air by controlling the size of the humidification and ventilation. The growth of natural plant fill system instituted the accurate "blue" and "red" energy balance. The improvement of spectral distribution makes the environment of crop growth better controlled, and makes the growth of crops faster and the quality improved. Window system refers to: when the temperature in the indoor climate beyond the set range, skylights and side windows can automatically open, so that the temperature of the indoor air convection, so as to adjust the indoor climate. The internal and external structure of the intelligent greenhouse is shown in Figure 2 and Figure 3. 


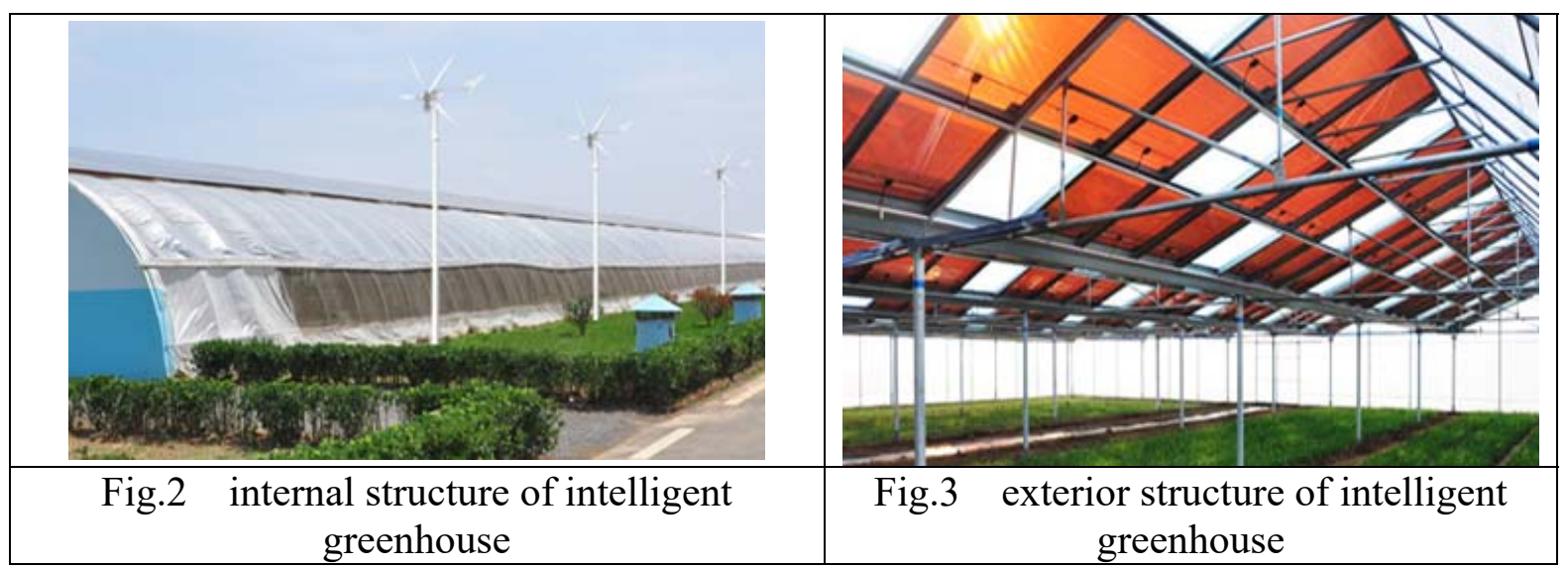

\section{Summary}

The combination of the Wind/PV Hybrid Generation industry agricultural development and resource conservation can achieve the goal of conservation of land, energy and resource. It uses the least input to achieve maximum benefit, and is committed to the coordinated development of economy and resources and environment. While vigorously developing wind energy and photovoltaic industry, we should adhere to the principle of saving and intensive land use and the principle of multiple use. Agricultural development insists on the principles of clean energy, such as wind energy and solar energy, and extends the chain of Wind/PV Hybrid industries to the development of agricultural science and technology.

\section{References}

[1] Guo Zikun. A Brief Discussion on the Application of Wind Power and Photovoltaic Combined Power Generation[J]. Mechatronics Information, 2017, (06): 22-23.

[2] Xu Yisheng. Discussion on Application Prospect of WPHGS in Expressway Service Area[J]. Traffic World, 2016, (Z1): 14-15.

[3] Yang Tengdong. Current Situation of Research on Wind/PV Hybrid Pumped Storage Power Station[J]. Guizhou Electric Power Technology, 2014, (07): 21-23.

[4] Du Du. Research and Present Situation of Wind/PV Hybrid Pumped Storage Power and Generation System[J]. Guizhou Electric Power Technology, 2014, (07): 59-61.

[5] Yang Junkai. Research on the Application of WPHGS in the Remote Area[J]. Low Carbon World, 2014, (11): 55-56.

[6] Xu Man. Development of Intelligent Microgrid System Based on Wind/PV Hybrid[J]. Science and Technology, 2013, (04): 23. 